\title{
A preventive immunization approach against insect bite hypersensitivity: Intralymphatic injection with recombinant allergens in Alum or Alum and Monophosphoryl Lipid A
}

Sigridur Jonsdottir ${ }^{*}$, Vilhjalmur Svansson ${ }^{1}$, Sara Bjork Stefansdottir ${ }^{1}$, Gertraud Schüpbach ${ }^{2}$

Claudio Rhyner ${ }^{3}$, Eliane Marti ${ }^{2 * *}$ and Sigurbjorg Torsteinsdottir ${ }^{1 * *}$

1) Institute for Experimental Pathology, Biomedical Center, University of Iceland, Keldur,

Keldnavegur 3, 112 Reykjavik, Iceland.

2) Department of Clinical Research and Veterinary Public Health, Vetsuisse Faculty, University of Berne, Länggass-Strasse 124, 3012 Berne, Switzerland.

3) Swiss Institute of Allergy and Asthma Research (SIAF), Davos, Switzerland.

**Equal contribution 
*Corresponding author: Sigridur Jonsdottir, sij9@ hi.is, Institute for Experimental Pathology, Biomedical Center, University of Iceland, Keldur, Keldnavegur 3, 112 Reykjavik, Iceland. 


\begin{abstract}
Insect bite hypersensitivity (IBH) is an IgE-mediated dermatitis of horses caused by bites of Culicoides insects, not indigenous to Iceland. Horses born in Iceland and exported to Culicoidesrich areas are frequently affected with IBH.

The aims of the study were to compare immunization with recombinant allergens using the adjuvant aluminum hydroxide (Alum) alone or combined with monophosphoryl lipid A (MPLA) for development of a preventive immunization against IBH.

Twelve healthy Icelandic horses were vaccinated intralymphatically three times with $10 \mu \mathrm{g}$ each of four recombinant Culicoides nubeculosus allergens in Alum or in Alum/MPLA. Injection with allergens in both Alum and Alum/MPLA resulted in significant increase in specific IgG subclasses and $\operatorname{IgA}$ against all r-allergens with no significant differences between the adjuvant groups. The induced antibodies from both groups could block binding of allergen specific IgE from IBH affected horses to a similar extent. No IgE-mediated reactions were induced. Allergen-stimulated PBMC from Alum/MPLA horses but not from Alum only horses produced significantly more IFNy and IL-10 than PBMC from non-vaccinated control horses. In conclusion, intralymphatic administration of small amounts of pure allergens in Alum/MPLA induces high IgG antibody levels and Th1/Treg immune response and is a promising approach for immunoprophylaxis and immunotherapy against IBH.
\end{abstract}




\section{Introduction}

Equine insect bite hypersensitivity (IBH), or summer eczema, is an allergic recurrent seasonal dermatitis of horses. It is caused by bites of insects mainly of the genus Culicoides (biting midges) (for review Schaffartzik et al., 2012) and characterized by papules and intense pruritus affecting the feeding sites of the midges (Bröstrom et al., 1987). IBH affects all horse breeds and is found almost worldwide with the exception of places where Culicoides species are not indigenous, as in Iceland (Illies, 1978). However, IBH is a severe problem in Icelandic horses exported from Iceland to the European continent. Over $50 \%$ of these horses develop the disease two years or more after importing into heavily Culicoides infested areas (Bjornsdottir et al., 2006), while Icelandic horses foaled in Europe develop the disease with a similar prevalence as most other horse breeds (Bröstrom et al., 1987). Presently, there is no satisfactory treatment of IBH (Schaffartzik et al., 2012), and thus preventive immunization may be an attractive option for horses exported from Iceland to countries where Culicoides are present. In humans, prophylactic immunotherapy to prevent allergic sensitization is not yet practiced but has been considered (Valenta et al., 2012). The allergen extracts mostly used in allergen immunotherapy are not suited as they risk inducing sensitization to other proteins in the mixture. For prophylactic treatment it is essential to use well-defined pure allergens and to treat before sensitization occurs (Valenta et al., 2012). IBH in Icelandic horses is thus an interesting model for development and study of prophylactic immunotherapy as Iceland is free of the causative agent and the horses are only sensitized after export. Furthermore, Culicoides allergens have been identified and characterized at the molecular level and are available as pure recombinant proteins (Mueller et al., 2016). 
According to our studies on the immune response and pathogenesis of IBH, Icelandic horses exported from Iceland to Europe develop a stronger Th2 polarized immune response than their disease status matched counterparts born in Switzerland (Hamza et al., 2007). Further studies demonstrated an imbalance between the Th2/Treg immune response in IBH, using both Culicoides stimulated PBMC and skin biopsies (Hamza et al., 2008; Hamza et al., 2013; Heimann et al., 2011). These findings indicate that a preventive immunization against IBH should aim at inducing an allergen-specific Treg and/or Th1 immune response.

Due to the high cost of production and purification of recombinant proteins and the risk of side effects when using a high dose of allergens (Klimek \& Pfaar, 2013) it is of great importance to have an efficient route of injection and a vigorous adjuvant to be able to use small amounts of the allergens. In a previous study we could show that when using the Th1 adjuvant IC $31^{\circledR}$ (Schellack et al., 2006) intralymphatic injection gave a slightly stronger immune response than intradermal injections (Jonsdottir et al., 2015). Based on these findings and on results from immunotherapy in humans (Senti et al., 2008), it was of interest to test further this injection route with other adjuvants.

Despite being a Th2 focusing adjuvant, Alum is the classical adjuvant used in immunotherapy for humans (Moingeon, 2012). However, when T-cell-mediated immunity is necessary additional components are needed (Brewer, 2006). Monophosphoryl lipid A (MPLA) is a detoxified derivative of lipopolysaccharide (LPS) that binds to Toll like receptor 4 (TLR4) and retains most of the adjuvant capacity of LPS (Evans et al., 2003; Qureshi et al., 1982). MPLA is used in vaccine formulations and has been registered for use in humans (Casella \& Mitchell, 2008). Since MPLA promotes primarily a Th1 type of response (Puggioni et al., 2005), it is being applied as an adjuvant in immunotherapy and has been shown to enhance specific 
IgG1 and IgG4 antibodies, and reduce allergy symptoms (Drachenberg et al., 2001; Mothes et al., 2003). The mixture of aluminum hydroxide and MPLA (AS04) is being used successfully in viral vaccines (Garçon et al., 2011).

The aim of our study was to compare the immune response induced by intralymphatic immunization with pure recombinant allergens in Alum alone or a mixture of Alum and MPLA in the search for optimal conditions for prophylactic immunotherapy against equine IBH. 


\section{Materials and methods}

\subsection{Animals}

Twelve healthy Icelandic horses, 7-10 years of age, were vaccinated. In addition three healthy horses were used as controls in the skin test and six horses as control in the in vitro stimulation of PBMC, age 5-13 years. All horses were living in Iceland. The experiment was performed in accordance with a permit from the National Animal Research Committee of Iceland (no. 011316).

\subsection{Vaccination and sample collection}

Twelve horses were vaccinated into the submandibular lymph nodes with four E.coli-expressed recombinant Culicoides nubeculosus allergens ( $\mathrm{rCul} \mathrm{n} \mathrm{3,} \mathrm{rCul} \mathrm{n} \mathrm{4,} \mathrm{rCul} \mathrm{n} 8$ and $\mathrm{rCul} \mathrm{n} \mathrm{10)}$ (Schaffartzik et al., 2011). The horses were vaccinated three times (week 0,4,8) with $10 \mu \mathrm{g}$ of each allergen. The horses were randomly divided into two groups. Six horses were vaccinated with the allergens in $500 \mu \mathrm{g}$ aluminum hydroxide gel (Alhydrogel ${ }^{\circledR} 2 \%$, Invivogen) and the other six with allergens in a mixture of Alum $(500 \mu \mathrm{g})$ and $50 \mu \mathrm{g}$ MPLA (Avantilipids). The total volume per vaccination was $400 \mu \mathrm{L}$. Blood was collected by jugular venipuncture at week 0 , every other week for 16 weeks, and then monthly until week 32 . Serum was stored at $-20^{\circ} \mathrm{C}$ until used. A differential count of leukocytes from EDTA blood was carried out (Jonsdottir et al., 2015).

\subsection{Production of Cul $\mathbf{n} 3$ in insect cells}

Cul n 3 was expressed in insect cells because pilot experiments had shown with E. coli derived Cul n 3 the cytokine production by PBMC was extremely low or absent, probably because this $E$. 
coli expressed protein precipitated in medium. The $C u l n 3$ gene was amplified from a $\lambda$ ZAPII cDNA library, made from salivary glands of $C$. nubeculosus (Schaffartzik et al., 2011), with primers (Fw: 5'- ATGCATAATTTTGCAGGGAT-3' and Re: 5'-

CGCATATGTGGTCAAAGTAG-3') designed based on the gene sequence of Cul n 3 (GenBank Accession No. HM145951). The protein was expressed in insect cells according to Bac-to-Bac ${ }^{\circledR}$ HBM-TOPO ${ }^{\circledR}$ Secreted Expression system. The Baculovirus was amplified in Sf-9 cells and the protein expressed in High five cells.

The Bac-rCul n 3 protein was purified under native conditions with HIS-Select ${ }^{\mathrm{TM}} \mathrm{HF}$ Nickel Affinity Gel (Sigma) in conformity with the manufacturer's protocol and dialyzed against PBS. The protein was analyzed with Coomassie blue staining (Wong et al., 2000) and detected with Cul n 3 specific polyclonal antibodies diluted 1:4000 (Schaffartzik et al., 2011) in WB (Fig. 1A) (Jonsdottir et al., 2015).

\subsection{Serological tests}

\subsubsection{ELISA}

Sera from six unvaccinated horses living in Iceland and from five IBH-affected horses living in Switzerland were included on each plate, as negative and positive controls, respectively. Allergen-specific antibody levels were determined by ELISAs as described in Jonsdottir et al., 2015 with the following changes. Plates were coated with $2 \mu \mathrm{g} / \mathrm{mL}$ of the recombinant allergens rCul n 3, rCul n 4, rCul n 8, rCul n 10 and Bac-rCul n 3. Sera (weeks 0, 2, 6, 10, 16) were added at a dilution of 1:5 for $\operatorname{IgE}$ detection, 1:10 for $\operatorname{IgA}$ (weeks $0,6,10,24,32$ ) and 1:200 for $\operatorname{IgG}$ subclasses (weeks $0,2,6,10,16,24,32$ ). Specific monoclonal antibodies were used for $\operatorname{IgG}$ 
subclasses and IgE detection as described by Jonsdottir et al., 2015 and for IgA, a monoclonal equine IgA specific antibody in a 1:250 dilution (Serotec) was applied.

\subsubsection{Competitive inhibition ELISA}

Pools of sera from the Alum group and Alum/MPLA group, containing the same amount of serum from each of the six horses, were used to analyze the ability of sera from vaccinated horses to block the IgE-binding of serum from an IBH-affected horse to the recombinant allergens. Pools of preimmune sera (negative control) and postimmune sera (two weeks after the third vaccination) were used in the competitive inhibition ELISA performed as described by Jonsdottir et al., 2015. The percentage of inhibition for each dilution of the pre- and postimmune serum pools was calculated.

\subsection{Stimulation of PBMC and determination of cytokines}

PBMC were isolated from the horses by Ficoll-Hypaque in conformity with Hamza et al., 2007 three weeks (week 11) after the $3^{\text {rd }}$ vaccination, and from six unvaccinated control horses. PBMC were stimulated for $24 \mathrm{hrs}$. (for RNA isolation) or for 4 days (for analysis of the supernatant) with ConA $(10 \mu \mathrm{g} / \mathrm{mL})$ as a positive control and Bac-rCul n $3(2 \mu \mathrm{g} / \mathrm{mL})$ or cultured in medium alone. The stimulation was performed in accordance with Jonsdottir et al., 2015. After 24 hrs., PBMC were harvested, lysed and homogenized in RA1 lysis buffer (Macherey-Nagel) and stored at $-80^{\circ} \mathrm{C}$ until used for total RNA isolation. After 4 days' incubation, cell supernatants were harvested and stored at $-80^{\circ} \mathrm{C}$ until cytokine measurement.

Determination of IL-4, IFNy and IL-10 in cell supernatants was performed at the Department of Population Medicine and Diagnostic Sciences, Cornell University, with bead-based multiplex assays (Wagner \& Freer, 2009). The values for the medium alone were subtracted and the results 
shown as mean and standard errors for each group as pg/mL for IL-4 and IL-10 and U/mL for IFNy. Total RNA isolation, Reverse Transcription of RNA and Q RT-PCR for Cytokine mRNA expression was performed as described previously (Jonsdottir et al., 2015).

\subsection{Skin test}

Skin tests were performed according to Schaffartzik et al. 2010, 2011 at week 30. In short, horses were injected in the lateral neck with $100 \mu \mathrm{L}$ of the allergens $\mathrm{rCul} \mathrm{n} \mathrm{3,4,8}$ and 10 diluted to 1 $\mu \mathrm{g} / \mathrm{mL}$ and $10 \mu \mathrm{g} / \mathrm{mL}$. Histamine $0.2 \mathrm{mg} / \mathrm{mL}$ was used as the positive control. Diameters of the wheal reaction at injection site were measured 30 min post injection.

\subsection{Statistical analyses}

Descriptive statistics were run on the IgG subclasses, IgA and IgE ELISA results using the statistical software NCSS 8 (NCSS Statistical Software, 329 North 1000 East, Kaysville, Utah 84037, USA). Antibody levels were log transformed because they were not normally distributed. Allergen-specific $\log I g G$ subclasses and $\log I g A$ levels were then analyzed using Proc Mixed of SAS (SAS Inst. Inc, Cary, NC). Week of measurement was included as a repeated effect, with the individual horse as the subject. Separate models were run with levels of $\log \operatorname{IgG} 1, \operatorname{IgG} 1 / 3$, IgG4/7, IgG5 and IgG(T) as outcome variable, respectively. The statistical model included effect of adjuvant (Alum or Alum/MPLA), recombinant allergen (rCul n 3, 4, 8, 10), and time (weeks after immunization: $0,2,6,10,16,24,32)$, and their interactions. Non-significant interactions were removed from the final model.

As the cytokine values were not distributed normally, the non-parametric ANOVA KruskalWallis Multiple-Comparison Z-Value Test was used to compare the differences on cytokine 
mRNA levels and in cytokines present in the supernatants in horses immunized with Alum, Alum/MPLA and non-immunized control horses. The Bonferroni correction was used to correct for multiple comparisons. Statistical significance was defined as $p<0.05$. 


\section{Results and discussion}

\subsection{Clinical examination}

The vaccinations in the submandibular lymph nodes were well tolerated. No rise in temperature or pain on palpation was observed, but mild local swelling occurred in a few cases. Leukocyte counts were within the normal range following vaccinations (data not shown). No difference was observed between vaccination with Alum or a mixture of Alum and MPLA.

\subsection{Specific antibody response of vaccinated horses}

Immunization with $10 \mu \mathrm{g}$ each of the four recombinant allergens led to a significant increase in all tested IgG subclasses as soon as two weeks after the first vaccination (Table 1), both in the Alum and Alum/MPLA groups, with further increase until week 10, i.e. 2 weeks after the $3^{\text {rd }}$ vaccination (Fig. 1B). Antibody levels then decreased until week 24 but were still significantly higher than before vaccination (Table 1). Interestingly, the intradermal test performed at week 30 boosted the specific antibody responses (Fig. 1B).

Comparison of the two groups of horses vaccinated with Alum or Alum/MPLA, showed a similar IgG subclass response in both groups (Table 1 and exemplified for Cul n 3 in Fig. 1B). Analysis of the data revealed significant differences in the IgG subclass levels between the different allergens. This confirms results from the previous study with the IC $31^{\circledR}$ adjuvant (Jonsdottir et al., 2015).

The Bac-rCul n 3 antibody response showed a similar pattern as when the E. coli-Cul n 3 was used in the ELISA (Fig. 1B). As expected the measured antibody increase was usually lower on Bac-rCul n 3 than on E. coli-rCul n 3 that was used for the vaccination. These results confirm 
that the antibody response is mainly raised against the $\mathrm{Cul} \mathrm{n} 3$ protein and not against the E. coli contamination of the recombinant proteins used for immunization (purity of 95\%).

As a protective role of IgA has been suggested in allergic diseases such as asthma (Gloudemans et al., 2013) and an increase in serum IgA is seen in allergen specific immunotherapy (Jutel et al., 2003), we also determined allergen-specific IgA levels in the sera. The horses in both groups had developed a significant IgA response against all four allergens (Table 1) already after the second immunization, as exemplified for rCul n3-specific IgA in Fig. 1B. The serum IgA levels were much lower than IgG as the sera could only be diluted 1:10 instead of 1:200 in the ELISA. No significant effect of MPLA could be observed on the IgA response compared to Alum alone.

Importantly immunization with the recombinant allergens did not induce sensitization as no IgE response was detected after the vaccinations, as exemplified for $\mathrm{rCul} n \mathrm{n}$ in Fig. 1B. Nor did the horses respond to the Culicoides allergens in intradermal tests, irrelevant of the adjuvant used (data not shown).

\subsection{Inhibition of allergen-specific IgE-binding by sera from the vaccinated horses}

An important factor in immunotherapy is the induction of $\mathrm{IgG}$ antibodies that can block the binding of IgE to the relevant allergens (Flicker \& Valenta, 2003). In the present study pools of the pre- and postimmune sera (two weeks after third vaccination) from the two groups of horses were tested in an inhibition ELISA. The inhibition of IgE-binding to $\mathrm{rCul} \mathrm{n} \mathrm{3,} \mathrm{rCul} \mathrm{n} 4$ and $\mathrm{rCul}$ n 10 was over $90 \%$ in the $1: 10$ serum dilution and still $60 \%$ or more in the $1: 40$ dilution.

Inhibition of binding to $\mathrm{rCul} \mathrm{n} 8$ was lower, around $70 \%$ in the 1:10 serum dilution and the 1:40 dilution had no inhibitory activity. This was regardless of the use of MPLA (Fig. 2). In our 
previous vaccination study (Jonsdottir et al., 2015) with the adjuvant IC $31^{\circledR}$, the blocking activity of the 1:10 diluted sera was lower, only reaching 18 to $54 \%$, depending on the allergen used. This result accords with higher antibody titers observed in the present study. However, we cannot distinguish whether this difference was due to the adjuvants or the allergens, as different recombinant Culicoides allergens were used. The inhibitory activity of the sera was also tested against Bac-rCul n 3 showing that the antibodies generated though immunization with $E$. coli expressed $\mathrm{Cul} \mathrm{n} 3$ were also able to efficiently inhibit IgE-binding to Bac-rCul n 3, although to a slightly lower extent (Fig. 2).

\subsection{IL-10, IFNy and IL-4 protein expression in PBMC stimulated in vitro with Bac-rCul n} 3

To further characterize the type of immune response induced by these adjuvants, PBMC were stimulated in vitro with Bac-rCul n 3 and the cytokine production determined. In contrast to the antibody response, there was a significant difference between the adjuvant groups in the cytokine responses. Upon stimulation of PBMC with Bac-rCul n 3 the horses vaccinated with the allergens in Alum/MPLA produced significantly more IFNy and IL-10 than the non-vaccinated controls, whereas this difference was not observed between the horses vaccinated with Alum and the control horses (Fig. 3). The same tendency was seen at the cytokine mRNA levels (data not shown). When the two vaccinated horse groups were compared without the controls the Alum/MPLA horses produced significantly more IFNy and IL-10 than the Alum horses. These findings suggest that MPLA is important to obtain the preferable Th1/Treg cytokine profile and shows that in horses, like humans, a combination of Alum and MPLA (AS04) induces a higher level of IFNy as compared to Alum alone (Didierlaurent et al., 2009). Notably, in our study 
Th1/Treg biased immune response induced by MPLA could not be detected in the antibody response.

\section{Conclusion}

In conclusion, our study confirms that also in horses, intralymphatic immunization enables the use of a small amount of allergens and relatively few injections for procuring a potent response. Importantly, because of the induction of a Th1/Treg immune response, Alum/MPLA seems an interesting combination for preventive allergen immunization. For further development of immunoprophylaxis and therapy against equine IBH these results need to be confirmed by determining the cytokine response using additional allergens and in allergen immunotherapy trials with IBH affected horses.

\section{Acknowledgments}

This work was supported by Icelandic Research Fund grant no 100408021-23, the Eimskip University Fund, the Agricultural Productivity Fund of Iceland, and Swiss National Science Foundation grant no. 310000-116803/1.

We are grateful to Dr. Bettina Wagner at the Department of Population Medicine and Diagnostic Sciences, College of Veterinary Medicine, Cornell University, Ithaca, NY 14853, USA who provided the IgG subclass antibodies and to Shui Ling Chu and Jelena Mirkovitch, Department of Clinical Research-VPH, Vetsuisse Faculty Bern, for their help with the ELISA. We are also 
grateful to Steinunn Árnadóttir for technical help, Sigurdur H. Helgason and Elvar H. Rikardsson for all their assistance with the horses. 


\section{References}

Bjornsdottir, S., Sigvaldadottir, J., Brostrom, H., Langvad, B., \& Sigurdsson, A. (2006). Summer eczema in exported Icelandic horses: influence of environmental and genetic factors. Acta Vet Scand, 48, 3.

Brewer, J. M. (2006). (How) do aluminium adjuvants work? Immunol Lett, 102(1), 10-15.

Bröstrom, H., Larsson, A., \& Troedsson, M. (1987). Allergic dermatitis (sweet itch) of Icelandic horses in Sweden: an epidemiological study. Equine Vet J, 19(3), 229-236.

Casella, C. R., \& Mitchell, T. C. (2008). Putting endotoxin to work for us: Monophosphoryl lipid A as a safe and effective vaccine adjuvant. Cell Mol Life Sci, 65(20), 3231-3240.

Didierlaurent, A. M., Morel, S., Lockman, L., Giannini, S. L., Bisteau, M., Carlsen, H., Kielland, A., Vosters, O., Vanderheyde, N., Schiavetti, F., Larocque, D., Van Mechelen, M., \& Garcon, N. (2009). AS04, an aluminum salt- and TLR4 agonist-based adjuvant system, induces a transient localized innate immune response leading to enhanced adaptive immunity. J Immunol, 183(10), 6186-6197.

Drachenberg, K. J., Wheeler, A. W., Stuebner, P., \& Horak, F. (2001). A well-tolerated grass pollenspecific allergy vaccine containing a novel adjuvant, monophosphoryl lipid A, reduces allergic symptoms after only four preseasonal injections. Allergy, 56(6), 498-505.

Evans, J. T., Cluff, C. W., Johnson, D. A., Lacy, M. J., Persing, D. H., \& Baldridge, J. R. (2003). Enhancement of antigen-specific immunity via the TLR4 ligands MPL adjuvant and Ribi.529. Expert Rev Vaccines, 2(2), 219-229.

Flicker, S., \& Valenta, R. (2003). Renaissance of the blocking antibody concept in type I allergy. Int Arch Allergy Immunol, 132(1), 13-24.

Garçon, N., Morel, S., Didierlaurent, A., Descamps, D., Wettendorff, M., \& Van Mechelen, M. (2011). Development of an AS04-Adjuvanted HPV Vaccine with the Adjuvant System Approach. BioDrugs, 25(4), 217-226.

Gloudemans, A. K., Lambrecht, B. N., \& Smits, H. H. (2013). Potential of immunoglobulin A to prevent allergic asthma. Clin Dev Immunol, 2013, 542091.

Hamza, E., Doherr, M. G., Bertoni, G., Jungi, T., \& Marti, E. (2007). Modulation of Allergy Incidence in Icelandic Horses Is Associated with a Change in IL-4-Producing T Cells. Int Arch Allergy Immunol, 144(4), 325-337.

Hamza, E., Wagner, B., Jungi, T. W., Mirkovitch, J., \& Marti, E. (2008). Reduced incidence of insect-bite hypersensitivity in Icelandic horses is associated with a down-regulation of interleukin- 4 by interleukin-10 and transforming growth factor- $\beta 1$. Vet Immunol Immunopathol, 122(1-2), 65-75.

Hamza, E., Akdis, C. A., Wagner, B., Steinbach, F., \& Marti, E. (2013). In vitro induction of functional allergen-specific CD4+ CD25high Treg cells in horses affected with insect bite hypersensitivity. Clin Exp Allergy, 43(8), 889-901.

Heimann, M., Janda, J., Sigurdardottir, O. G., Svansson, V., Klukowska, J., von Tscharner, C., Doherr, M., Broström, H., Andersson, L. S., Einarsson, S., Marti, E., \& Torsteinsdottir, S. (2011). Skininfiltrating $\mathrm{T}$ cells and cytokine expression in Icelandic horses affected with insect bite hypersensitivity: A possible role for regulatory T cells. Vet Immunol Immunopathol, 140(1-2), 6374.

Illies, J. (1978). Limnofauna Europaea. Stuttgart, New York: Gustav Fischer Verlag.

Jonsdottir, S., Hamza, E., Janda, J., Rhyner, C., Meinke, A., Marti, E., Svansson, V., \& Torsteinsdottir, S. (2015). Developing a preventive immunization approach against insect bite hypersensitivity using recombinant allergens: A pilot study. Vet Immunol Immunopathol, 166(1-2), 8-21.

Jutel, M., Akdis, M., Budak, F., Aebischer-Casaulta, C., Wrzyszcz, M., Blaser, K., \& Akdis, C. A. (2003). IL-10 and TGF-beta cooperate in the regulatory T cell response to mucosal allergens in normal immunity and specific immunotherapy. Eur J Immunol, 33(5), 1205-1214.

Klimek, L., \& Pfaar, O. (2013). A comparison of immunotherapy delivery methods for allergen immunotherapy. Expert Rev Clin Immunol, 9(5), 465-474; quiz 475. 
Moingeon, P. (2012). Adjuvants for allergy vaccines. Hum Vaccin Immunother, 8(10), 1492-1498.

Mothes, N., Heinzkill, M., Drachenberg, K. J., Sperr, W. R., Krauth, M. T., Majlesi, Y., Semper, H., Valent, P., Niederberger, V., Kraft, D., \& Valenta, R. (2003). Allergen-specific immunotherapy with a monophosphoryl lipid A-adjuvanted vaccine: reduced seasonally boosted immunoglobulin E production and inhibition of basophil histamine release by therapy-induced blocking antibodies. Clin Exp Allergy, 33(9), 1198-1208.

Mueller, R. S., Janda, J., Jensen-Jarolim, E., Rhyner, C., \& Marti, E. (2016). Allergens in veterinary medicine. Allergy, 71(1), 27-35.

Puggioni, F., Durham, S. R., \& Francis, J. N. (2005). Monophosphoryl lipid A (MPL) promotes allergeninduced immune deviation in favour of Th1 responses. Allergy, 60(5), 678-684.

Qureshi, N., Takayama, K., \& Ribi, E. (1982). Purification and structural determination of nontoxic lipid A obtained from the lipopolysaccharide of Salmonella typhimurium. J Biol Chem, 257(19), 11808-11815.

Schaffartzik, A., Marti, E., Torsteinsdottir, S., Mellor, P. S., Crameri, R., \& Rhyner, C. (2011). Selective cloning, characterization, and production of the Culicoides nubeculosus salivary gland allergen repertoire associated with equine insect bite hypersensitivity. Vet Immunol Immunopathol, 139(24), 200-209.

Schaffartzik, A., Hamza, E., Janda, J., Crameri, R., Marti, E., \& Rhyner, C. (2012). Equine insect bite hypersensitivity: What do we know? Vet Immunol Immunopathol, 147(3-4), 113-126.

Schellack, C., Prinz, K., Egyed, A., Fritz, J. H., Wittmann, B., Ginzler, M., Swatosch, G., Zauner, W., Kast, C., Akira, S., von Gabain, A., Buschle, M., \& Lingnau, K. (2006). IC31, a novel adjuvant signaling via TLR9, induces potent cellular and humoral immune responses. Vaccine, 24(26), 5461-5472.

Senti, G., Prinz Vavricka, B. M., Erdmann, I., Diaz, M. I., Markus, R., McCormack, S. J., Simard, J. J., Wuthrich, B., Crameri, R., Graf, N., Johansen, P., \& Kundig, T. M. (2008). Intralymphatic allergen administration renders specific immunotherapy faster and safer: a randomized controlled trial. Proc Natl Acad Sci U S A, 105(46), 17908-17912.

Valenta, R., Campana, R., Marth, K., \& van Hage, M. (2012). Allergen-specific immunotherapy: from therapeutic vaccines to prophylactic approaches. J Intern Med, 272(2), 144-157.

Wagner, B., \& Freer, H. (2009). Development of a bead-based multiplex assay for simultaneous quantification of cytokines in horses. Vet Immunol Immunopathol, 127(3-4), 242-248.

Wong, C., Sridhara, S., Bardwell, J., \& Jakob, U. (2000). Heating greatly speeds Coomassie blue staining and destaining. Biotechniques, 28(3), 426-428, 430, 432. 


\section{Figure legend}

\section{Figure 1: A) Purification and detection of Bac-rCul n 3 produced in High five insect cells.}

Coomassie blue staining (CB) and Western blot (WB) of purified Bac-rCul n 3 in PBS, detected with Cul n 3 specific polyclonal antibody (1:4000). B) Cul n 3 specific antibody response. Time course of IgG subclass, IgA and IgE response against $E$. coli-rCul n 3 measured by ELISA and comparison of IgG subclass response against Bac-Cul n 3. Corrected OD mean values and standard error for the six horses in the two groups at different time points, Alum ( - ) and Alum/MPLA (- - -). The first three arrows indicate the vaccination time points and the last the intradermal test.

Figure 2: Inhibition of IgE binding to the allergens with pool of sera from the two vaccination groups. Mean percent inhibition by pre and post vaccination sera from the two groups, diluted 1:10 - 1:160 applied to an ELISA plate coated with allergens, prior to adding serum from an IBH positive horse at a dilution 1:5. Preimmune sera Alum horses (—○一), preimmune sera

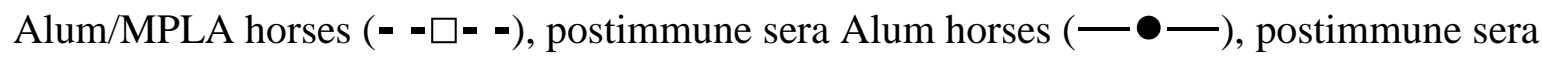
Alum/MPLA horses (- - $\mathbf{-}-\boldsymbol{-})$.

Figure 3: Detection of IL-4, IL-10 and IFNy after in vitro stimulation of PBMC from the Alum and Alum/MPLA vaccinated horses and six control horses. The cytokines were measured in supernatants using bead-based multiplex assays. Comparisons were performed using Kruskal- 
Wallis Multiple Comparison Z value Tests with Bonferroni corrections. An asterisk (*) with line indicates statistically significant differences between the groups of horses. 


\section{CB WB}

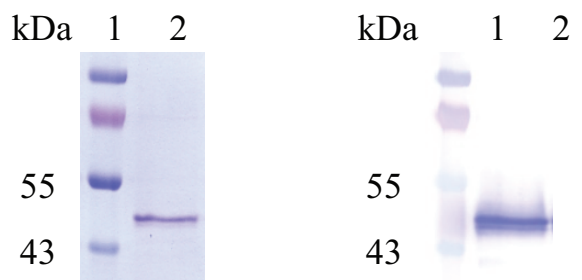

B

IgG1

Bac-rCul n 3
IgG4/7

Bac-rCul n 3

\section{IgG5}

Bac-rCul n 3

\section{$\operatorname{IgG}(\mathrm{T})$}

Bac-rCul n 3
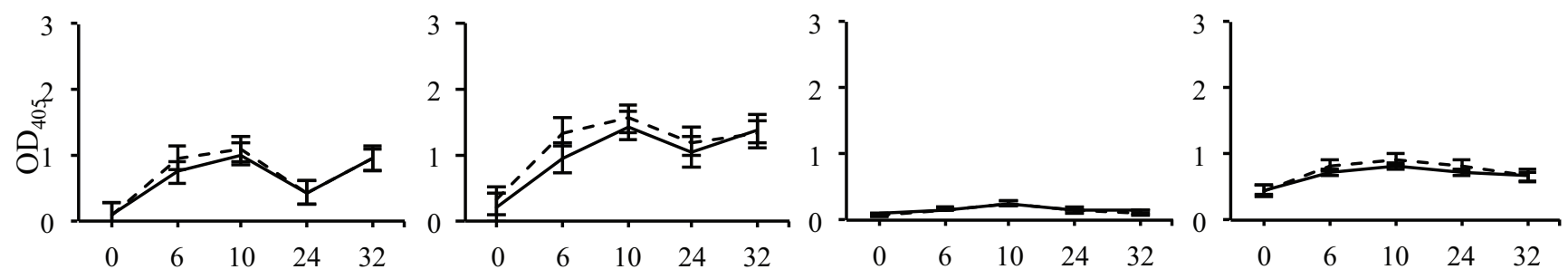

E.coli-rCul n 3

E.coli-rCul n 3

E.coli-rCul n 3

E.coli-rCul n 3
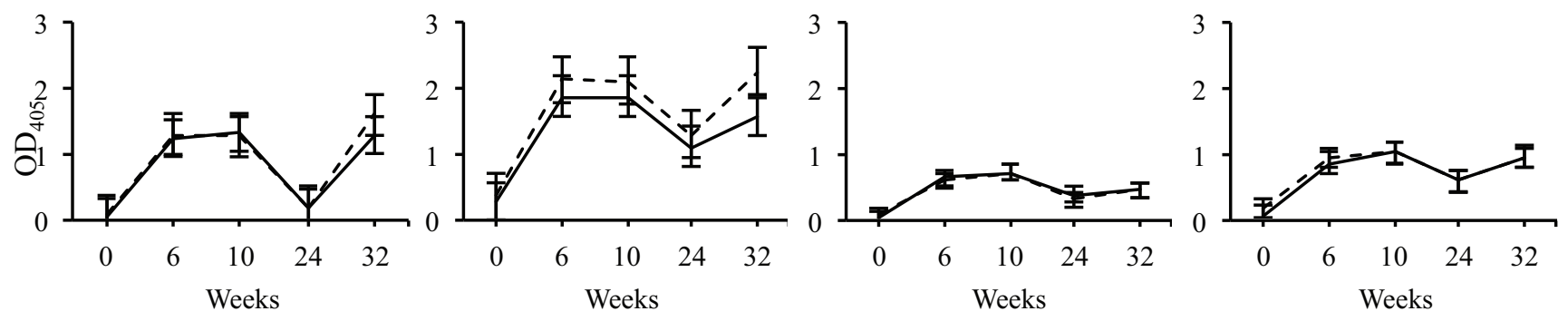

$\uparrow 4$

4
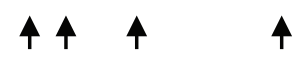

44

\section{IgA}

E.coli-rCul n 3

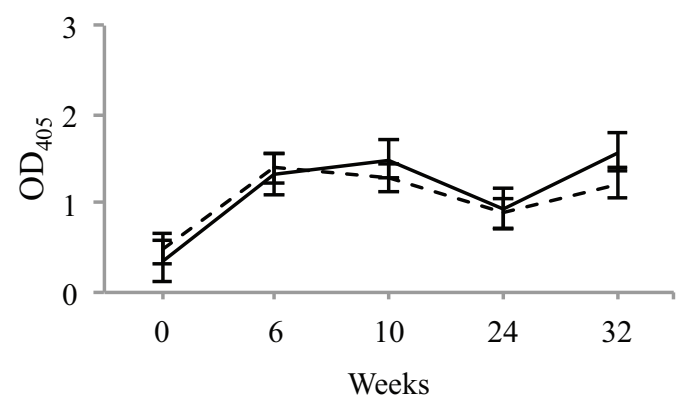

4

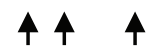

\section{IgE}

E.coli-rCul n 3

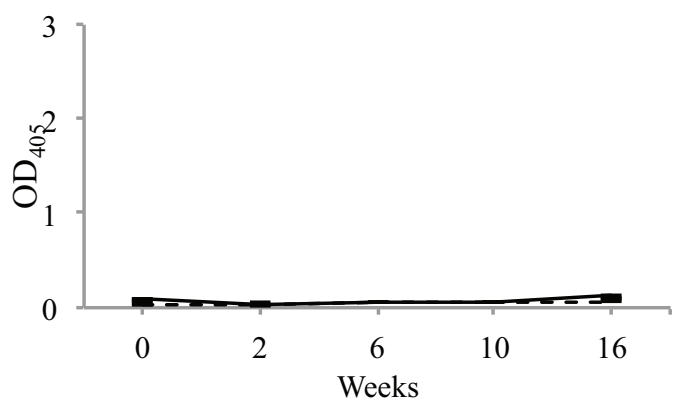


IL-4

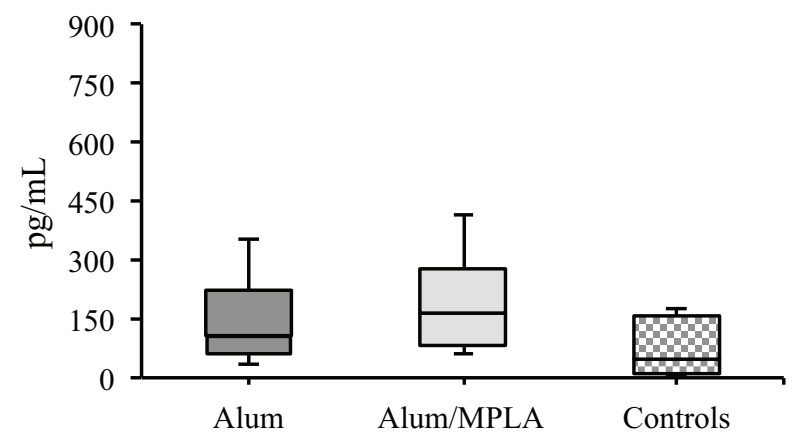

IFN-Y

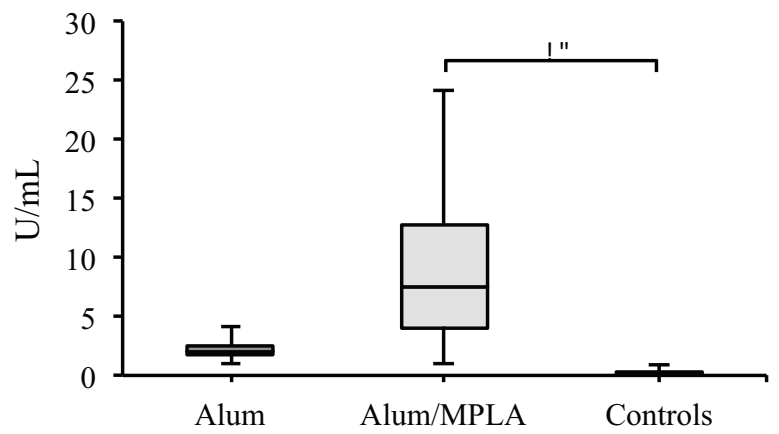

\section{IL-10}

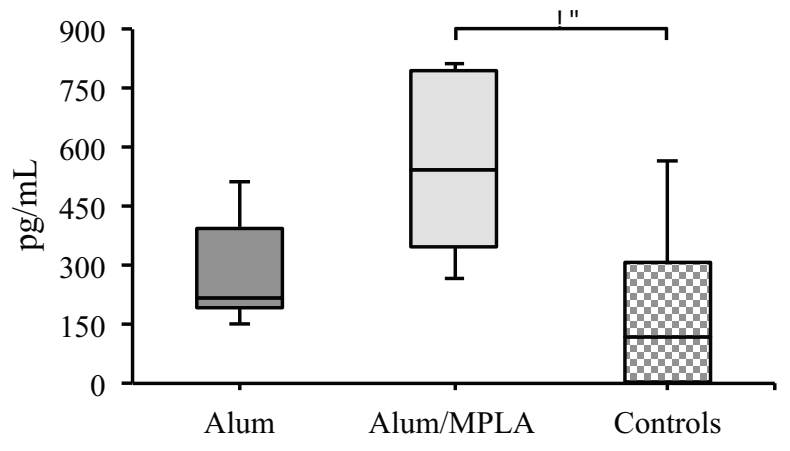


Table 1: Mixed linear regression model of association between log-transformed levels of IgG subclasses and adjuvant and allergens with time (weeks after immunization) as repeated effect.

\begin{tabular}{|c|c|c|c|c|c|c|c|c|c|c|c|c|c|c|c|c|c|c|}
\hline \multirow[b]{2}{*}{ Effect } & \multicolumn{3}{|c|}{$\log \lg G 1$} & \multicolumn{3}{|c|}{$\log \lg G 1 / 3$} & \multicolumn{3}{|c|}{$\log \lg G 4 / 7$} & \multicolumn{3}{|c|}{$\log \operatorname{lgG} 5$} & \multicolumn{3}{|c|}{$\log \operatorname{lgG}(T)$} & \multicolumn{3}{|c|}{$\log \lg A$} \\
\hline & Estimate & SE & $\mathrm{p}$-value & Estimate & $\mathrm{SE}$ & $\mathrm{p}$-value & Estimate & SE & $p$-value & Estimate & SE & $p$-value & Estimate & SE & $\mathrm{p}$-value & Estimate & $\mathrm{SE}$ & $\mathrm{p}$-value \\
\hline \multicolumn{19}{|l|}{ Adjuvant } \\
\hline Alum/ MPLA & 0.23 & 0.05 & $<.01$ & 1.27 & 0.21 & $<.001$ & 0.01 & 0.02 & .60 & -0.04 & 0.05 & .48 & -0.06 & 0.03 & $<.05$ & -0.06 & 0.03 & .08 \\
\hline \multicolumn{19}{|l|}{ Allergen } \\
\hline Cul n $3^{b}$ & 0.20 & 0.03 & $<.0001$ & 1.75 & 0.21 & $<.0001$ & -0.27 & 0.07 & $<.001$ & 1.12 & 0.19 & $<.0001$ & 0.20 & 0.04 & $<.0001$ & 0.22 & 0.05 & $<.0001$ \\
\hline Cul n $4^{b}$ & 0.26 & 0.03 & $<.0001$ & 1.70 & 0.21 & $<.0001$ & 0.01 & 0.07 & .87 & 0.27 & 0.19 & .18 & 0.23 & 0.04 & $<.0001$ & 0.06 & 0.05 & .21 \\
\hline Cul n $10^{b}$ & 0.12 & 0.03 & $<.001$ & 1.29 & 0.21 & $<.0001$ & -0.02 & 0.07 & .75 & 0.57 & 0.19 & $<.01$ & 0.19 & 0.04 & $<.0001$ & 0.23 & 0.05 & $<.0001$ \\
\hline \multicolumn{19}{|l|}{ Week } \\
\hline $2^{c}$ & 1.25 & 0.05 & $<.0001$ & 2.94 & 0.21 & $<.0001$ & 0.42 & 0.07 & $<.0001$ & 2.00 & 0.20 & $<.0001$ & 1.04 & 0.05 & $<.0001$ & nd & & \\
\hline $6^{c}$ & 1.46 & 0.05 & $<.0001$ & 3.12 & 0.21 & $<.0001$ & 0.54 & 0.07 & $<.0001$ & 2.43 & 0.20 & $<.0001$ & 1.32 & 0.05 & $<.0001$ & 0.60 & 0.05 & $<.0001$ \\
\hline $10^{c}$ & 1.47 & 0.05 & $<.0001$ & 3.13 & 0.21 & $<.0001$ & 0.53 & 0.07 & $<.0001$ & 2.49 & 0.20 & $<.0001$ & 1.36 & 0.05 & $<.0001$ & 0.64 & 0.05 & $<.0001$ \\
\hline $16^{c}$ & 0.95 & 0.05 & $<.0001$ & 2.44 & 0.21 & $<.0001$ & 0.47 & 0.07 & $<.0001$ & 2.08 & 0.20 & $<.0001$ & 1.25 & 0.05 & $<.0001$ & 0.34 & 0.05 & $<.0001$ \\
\hline $24^{c}$ & 0.61 & 0.05 & $<.0001$ & 2.18 & 0.21 & $<.0001$ & 0.28 & 0.07 & $<.0001$ & 1.67 & 0.20 & $<.0001$ & 1.07 & 0.05 & $<.0001$ & nd & & \\
\hline $32^{c}$ & 1.33 & 0.05 & $<.0001$ & 2.95 & 0.21 & $<.0001$ & 0.50 & 0.07 & $<.0001$ & 2.01 & 0.20 & $<.0001$ & 1.27 & 0.05 & $<.0001$ & 0.55 & 0.05 & $<.0001$ \\
\hline \multicolumn{19}{|l|}{ Interactions } \\
\hline$\overline{\text { Adjuvant*week }}$ & & & & & & & & & ns & & & ns & & & ns & & & ns \\
\hline Alum/MPLA*2d & -0.15 & 0.07 & $<.05$ & -1.23 & 0.29 & $<.0001$ & & & & & & & & & & & & \\
\hline Alum/MPLA* $6^{d}$ & -0.20 & 0.07 & $<.01$ & -1.25 & 0.29 & $<.0001$ & & & & & & & & & & & & \\
\hline Alum/MPLA*10d & -0.21 & 0.07 & $<.01$ & -1.23 & 0.29 & $<.0001$ & & & & & & & & & & & & \\
\hline Alum/MPLA*16d & -0.25 & 0.07 & $<.01$ & -1.39 & 0.29 & $<.0001$ & & & & & & & & & & & & \\
\hline Alum/MPLA*24d & -0.23 & 0.07 & $<.01$ & -1.40 & 0.29 & $<.0001$ & & & & & & & & & & & & \\
\hline Alum/MPLA*32d & $-0-07$ & 0.07 & .28 & -1.10 & 0.29 & $<.0001$ & & & & & & & & & & & & \\
\hline Allergen*week & & & ns & & & $<.0001$ & & & $<.05$ & & & $<.05$ & & & ns & & & ns \\
\hline $\begin{array}{l}\text { Adjuvant*allergen } \\
{ }^{*} \text { week }\end{array}$ & & & ns & & & $<.05$ & & & ns & & & ns & & & ns & & & ns \\
\hline
\end{tabular}

a vs Alum: these significant differences for $\lg G 1$ and $\operatorname{lgG} 1 / 3$ and the resulting significant interaction between adjuvans* week, were due to the fact that mean IgG1 and IgG1/3 levels at week 0 in the Alum/MPLA group were slightly but consistently higher than in the Alum group (data not shown).

${ }^{\mathrm{b}}$ vs Cul n 8

${ }^{c}$ vs week 0

${ }^{\mathrm{d}}$ vs Alum*corresponding week

nd $=$ not done 